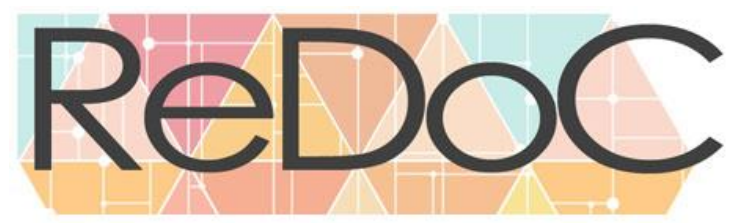

Revista Docência e Cibercultura

\title{
"EU GOSTO MESMO É DAS BIXAS" \\ REFLEXÕES SOBRE IDENTIDADE AO SOM DE LINN DA QUEBRADA
}

\author{
"I LIKE SAME IS FROM THE BIXAS" \\ REFLECTIONS ON IDENTITY TO LINN DA QUEBRADA'S SOUND
}

\section{"YO GUSTO MISMO ES DE LAS BIXAS" \\ REFLEXIONES SOBRE IDENTIDAD AL SONIDO DE LINN DA QUEBRADA}

\author{
Ariel Dorneles Dos Santos ${ }^{1}$ \\ Tiago Duque ${ }^{2}$
}

\section{RESUMO}

O presente trabalho apresenta uma análise do funk e do discurso utilizado por Linn da Quebrada, moradora de uma comunidade da Zona Leste da cidade de São Paulo. Em suas palavras, ela se identifica como "uma bixa, transviada, uma bixa travesti, periférica, preta que está experimentando o corpo e está se jogando". A metodologia utilizada é a etnografia virtual, através de videoclipes e entrevistas da cantora disponíveis em diferentes canais na plataforma do YouTube. O referencial teórico é, principalmente, o pós-estruturalista, com ênfase na perspectiva queer. Considerando a forma como Linn da Quebrada refere-se ao seu próprio corpo e identidade, percebe-se a priore que ela parece apresentar uma dissidência dentro da dissidência por não ser cisgênera e também borrar o que se entende por ser travesti, contudo, essa ideia é problematizada devido ao fato de em alguns momentos borrar a norma, mas, em outros, reiterá-la. Sua experiência de identificação parece ser como a de um elemento que não cabe em nenhuma categoria, mas que se apossa das que foram designadas e as subverte, contestando e apresentando novas possibilidades, novos processos de inteligibilidade/reconhecimento.

PALAVRAS-CHAVE: Transviada. Dissidência. Identidade. Linn da Quebrada

\begin{abstract}
This work presents an analysis of the funk and discourse used by Linn da Quebrada, a resident of a community in the East Zone of the city of São Paulo. In her words, she identifies herself as "a bixa, transviada, a bixa transvestite, periférica, black, who is experiencing the body and is playing." The methodology used is virtual ethnography, through video clips and interviews of the singer available in different channels on the YouTube platform. The theoretical reference is, mainly, the poststructuralist, with emphasis on the queer perspective. Considering the way Linn da Quebrada refers to her own body and identity, it is perceived that she seems to present a dissidence within the dissidence because she is not a cisgênera and also to erase what is meant by being a transvestite, however, this idea is problematized due to the fact that at times it erases the norm, but in others it reiterates it. His experience of identification seems to be like that of an element that does not fit into any category, but that takes hold of those that have been assigned and subverts them, challenging and presenting new possibilities, new processes of
\end{abstract}

Submetido em: 28/02/2019

Aceito em: 10/04/2019

Publicado em: 01/06/2019

1 Mestranda em Antropologia Social pela Universidade Federal de Mato Grosso do Sul. Orcid: https://orcid.org/0000-0003-4534-3501

${ }^{2}$ Doutor em Ciências Sociais pela UNICAMP e professor da Faculdade de Ciências Humanas da Universidade Federal de Mato Grosso do Sul. Orcid: https://orcid.org/0000-0003-1831-0915 


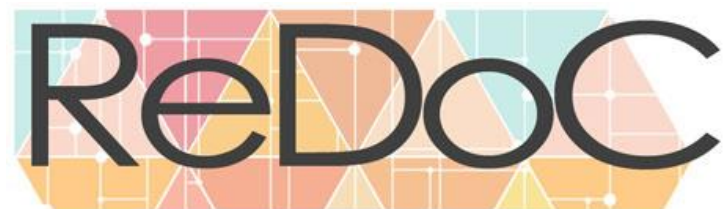

Revista Docência e Cibercultura

intelligibility/recognition.

KEYWORDS: Transvestite. Dissent. Identity. Linn da Quebrada.

\section{RESUMEN}

El presente trabajo presenta un análisis del funk y del discurso utilizado por Linn da Quebrada, residente de una comunidad de la Zona Este de la ciudad de São Paulo. En sus palabras, ella se identifica como "una 'bixa', transviada, una 'bixa' travesti, periférica, negra que está experimentando el cuerpo y se está jugando". La metodología utilizada es la etnografía virtual, a través de videoclips y entrevistas de la cantante disponibles en diferentes canales en la plataforma de YouTube. El referencial teórico es, principalmente, el post-estructuralista, con énfasis en la perspectiva queer. En cuanto a la forma en que Linn da Quebrada se refiere a su propio cuerpo e identidad, se percibe la priore que ella parece presentar una disidencia dentro de la disidencia por no ser cisgénera y también borrar lo que se entiende por ser travesti, sin embargo, esa idea es problematizada debido al hecho de que en algunos momentos borrar la norma, pero, en otros, reiterarla. Su experiencia de identificación parece ser como la de un elemento que no cabe en ninguna categoría, sino que se apuesta de las que fueron designadas y las subvierte, contestando y presentando nuevas posibilidades, nuevos procesos de inteligibilidad/reconocimiento.

PALABRAS CLAVE: Transviada. Disidencia. Identidad. Linn da Quebrada

\section{Introdução}

Nos últimos anos tem crescido a visibilidade de artistas trans ${ }^{4}$ até então consideradas/os à margem da sociedade devido a não adesão aos padrões hegemônicos no que diz respeito a gênero, sexualidade, estética e performance no geral. Contudo, essa visibilidade não tem apenas dado voz/visibilidade/reconhecimento midiático a essas pessoas, suas representações identitárias e seus perfis considerados inadequados. Ela também tem levantado questionamentos a despeito das identidades não heteronormativas ${ }^{5}$ e não cisgêneras $^{6}$, que comumente são alocadas como monstros que devem ser temidos por tensionarem a estabilidade social.

\footnotetext{
${ }^{4}$ As travestis/transexuais: Mc Xuxu, Liniker, Assucena e Raquel Virgínia da banda As Bahias e a Cozinha Mineira; e as Drag Queens: Pabllo Vittar, Gloria Groove, Lia Clark. Disponível em: $<$ https://mdemulher.abril.com.br/cultura/11-artistas-brasileiros-que-estao-quebrando-todas-as-regras-degenero/>. Acesso em: 14 jan. 2019.

${ }^{5}$ Warner (1991 apud SANTOS e DINIS, 2013) define a heteronormatividade como um processo de legitimidade e privilégio que se relacionam com a heterossexualidade por pressupor essa como algo "natural".

${ }^{6}$ Vergueiro, em entrevista para Ramírez (2014), considera o termo cisgeneridade um ponto analítico para se contestar a naturalidade com que as pessoas não trans são legitimidadas, permitindo um olhar descolonial do gênero, inclusive, na substituição desse termo por outros como "mulher biológica", "homem de verdade", deslocando também a hierarquia e a naturalidade construída. É, portanto, a cisgeneridade não somente uma classificação de uma certa adequação de um sujeito quanto ao gênero que lhe é classificado a partir da genitáliasexo, mas uma categoria política de revisar o que se considera como padrão e essencial.
} 


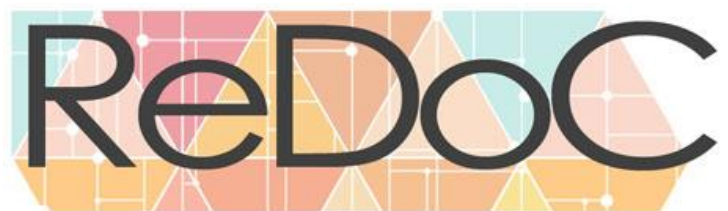

Revista Docência e Cibercultura

Em uma tentativa de oposição a isso, Miskolci (2010) aponta que os movimentos sociais organizados pela população LGBT (Lésbicas, Gays, Bissexuais, Travestis e Transexuais), por exemplo, apresentam discursos que tentam igualar essas identidades dissidentes com as ditas normais. Discursos esses, muitas vezes, pautados por um essencialismo que tenta colocar no mesmo grau de legitimidade as identidades LGBT das 'cis-heteronormativas', caracterizandoas como inerentes aos sujeitos e não adquiridas, construídas, mutáveis.

Linn da Quebrada ${ }^{7}, 28$ anos, moradora de uma comunidade da Zona Leste da cidade de São Paulo, é um exemplo das atuais possibilidades de identidade que tende a fugir desses dois grupos identitários apresentados no parágrafo anterior (heteronormativos e cisgêneros). Ela tem ganhado grande destaque, sobretudo no campo da música. Com uma estética fora dos padrões - sendo uma travesti negra sem silicone, utilizando ambas as roupas consideradas femininas e masculinas, comumente com cabelos coloridos e/ou com penteados afro (como trança nagô, dread), mas às vezes careca. Linn destoa do padrão tanto de uma suposta normatividade 'cis' quanto de um perfil esperado de travesti. Ela defende a necessidade de se mostrar como deseja, independente dos padrões: “A estética é uma experiência política que tem total influência sobre os nossos afetos. A maneira como você se veste esteticamente gera efeito não somente em outras pessoas como gera efeitos em você também" $"$.

Em suas palavras, ela se identifica como "uma bixa transviada, uma bixa travesti, periférica, preta que está experimentando o corpo e está se jogando" ". Ou seja, Linn se apropria, tal como nos remete a teoria queer ${ }^{10}$, de nomes considerados xingamentos na construção da imagem de

\footnotetext{
${ }^{7}$ Linn sempre se apresenta com a backing vocal Jup do Bairro que também se coloca como "bixa travesti”. Jup é uma figura importante nas performances, pois sendo negra e gorda apresenta e fala de seu corpo em forma de protesto de um corpo livre, bem como auxilia Linn nas criações das músicas. No entanto, aqui, por questões de recorte do "objeto" de estudo, focaremos apenas em Linn.

${ }^{8}$ Entrevista disponível em: 〈https://www.youtube.com/watch?v=jBEKL9lnYGA>. Acesso em: 14 mar. 2017.

${ }^{9}$ Idem.

${ }^{10}$ Teoria queer é um termo usado por Teresa de Laurentis em uma conferência em 1990 sobre a sexualidade de gays e lésbicas. Antes, a categoria acusatória/estigmatizada 'queer', sem tradução para o português, foi apropriada pelo movimento social anti-assimilacionista americano diante da pauta mais conservadora do Movimento Gay. Hoje em dia, a teoria parte da pluralidade da diversidade de identidades encontradas na sociedade, é, por isso, uma teoria que questiona os conceitos de identidades essencializadas, voltando-se não somente para as identidades mais marginalizadas, como também aos processos de construção e desconstrução identitárias, revendo conceitos de poder da divisão binária dos sexos/gêneros (LOURO, 2001). Contudo, o termo queer se refere, em inglês, a
} 


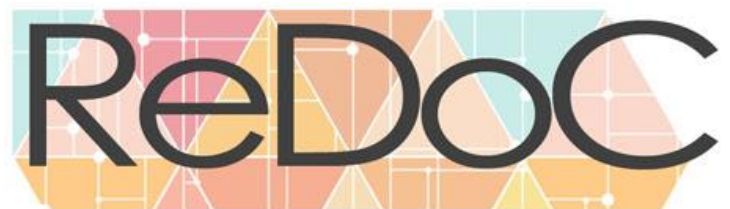

\section{Revista Docência e Cibercultura}

sua identidade, mas vai além ao quebrar expectativas de desejos, discursos e comportamentos a ela estereotipados.

A diferenciação de Linn de outras travestis tem relação direta com as mudanças históricas que a experiência de 'montagem' do corpo travesti tem sofrido. 'Montagem' refere-se ao ato de vestir-se com roupas consideradas de mulher. Benedetti (2000), ao estudar travestis, a classificou como um processo de manipulação e construção de uma apresentação que seja suficientemente convincente, sob o ponto de vista delas, de sua qualidade feminina, do que é entendido por elas como feminino. No caso desse grupo, o convencimento é garantido também através de outras ações que podem compor a 'montagem' em um sentido mais amplo, como os hormônios femininos adotados por elas desde o final da década de 1960 (GREEN, 2000), e a técnica de aplicação do silicone líquido que, apesar dos avanços no campo das cirurgias estéticas, continua sendo comum. Segundo Silva (1993), todo o esforço delas é em busca de um "passar por" possibilidade" (Idem, p. 129). Vale ressaltar que esse é um modelo encontrado pelo autor da experiência travesti que se apresentava e se reiterava em suas pesquisas sem ser, necessariamente, uma tentativa de essencializar essa identidade. Assim, hoje, na 'montagem' realizada pela maior parte das travestis, ainda que tenha sido cada vez mais comum uma nova geração de travestis lidar de forma menos definitiva com as transformações corporais (DUQUE, 2011), há uma busca de naturalidade que comumente Linn não tem.

Essa pesquisa, em uma perspectiva pós-estruturalista (pós-colonial, feminista e queer), analisa os videoclipes do YouTube, além de diversas entrevistas também disponíveis na mesma plataforma. Conforme Miskolci (2011), o uso de mídias sociais tende a atingir uma grande massa, contudo, sem ser necessariamente algo universalizante e, por isso, tem crescido notoriamente em diversos ramos de pesquisa. O YouTube é aqui usado como ambiente de

uma população mais específica, população essa que não pode ser restrita apenas aos LGBTs, mas a todas as pessoas que de alguma forma tornam-se dissidentes por conta de suas práticas, experiências.

${ }^{11}$ Para uma leitura mais aprofundada sobre o 'passar por', inclusive sobre as justas motivações em torno desse processo de passabilidade por experiências de menos vulneráveis diante da violência e do preconceito, ler Duque (2017). 


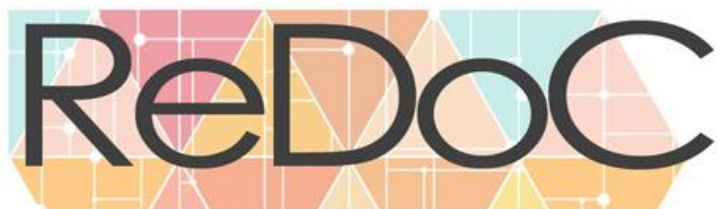

\section{Revista Docência e Cibercultura}

acesso e interação com o conteúdo produzido por Linn, sendo uma das mídias sociais de grande impacto percebido pelo grande número de acesso à plataforma (leia-se aos vídeos) e pela quantidade de material disponível. Essa plataforma é aqui utilizada como processo de acesso ao conteúdo e, em certa medida, um ponto de problematização, mas não é o elemento principal da análise por conta da notória fama que a cantora parece ter na internet. Contudo, torna-se importante mencionar que essa plataforma possui complexidades, projetos de agenciamentos, mecanismo políticos e de disputa de poder, mas que não cabe a esse estudo se aprofundar.

A busca pelo conteúdo relacionado a Linn se deu ao digitar o nome dela na plataforma e acessar tanto os conteúdos que aparecem como 'Relevância' pelo YouTube, ou seja, os que possuem mais curtidas, comentários e visualizações, como pela classificação de 'Data de envio'. Assim, foi possível explorar, em ordem cronológica, se houve ou não alteração na proposta que a cantora tem apresentado, bem como quais espaços ela passou a acessar. Uma maior evidência da sua imagem possibilitou que ela fosse entrevistada em canais que não estão diretamente relacionados com temática sobre identidade, gênero, sexualidade, funk etc. Portanto, a incursão na plataforma ocorreu de maneira a acessar a cantora nos mais variados espaços possíveis, tendo em vista que no próprio canal dela comportam especificamente os videoclipes e shows.

Essa análise se vincula ao processo de etnografia virtual. Segundo Adriana Amaral (2010), ele se realiza via uma reflexão imersa no campo digital (no caso, a internet) percebendo a relação e relevância desse campo para com a pesquisa em si. Tendo em vista que o acesso ao conteúdo da cantora parte de um ambiente onde esse está disponível no YouTube e não está de modo offline, ou seja, independente de internet, a busca foi sempre online, verificando assim as possibilidades de mudanças do conceito de 'Relevância' dos vídeos do YouTube que são constantemente atualizados.

\section{Linn da Quebrada e as normas identitárias de gênero}

n.1

p. 17 
Apesar da teoria queer não propor necessariamente uma nova identidade, mas sim a legitimação das experiências já existentes, muitos sujeitos têm se apropriado dela - apesar de muitas dessas experiências dissidentes anteverem a concepção teórica -, para proclamar-se como uma possibilidade em meio a um sistema de produção e manutenção de uma lógica hegemônica 'cis-heteronormativa' (vale ressaltar, contudo, que alguns sujeitos também buscam fazer parte dessa hegemonia). Um exemplo é a Linn da Quebrada que, através do funk ${ }^{12}$, demonstra a desestabilização desse sistema nos revelando sujeitos até então não reconhecidos socialmente, não legitimados, ressignificando, evidenciando subjetividades e estabelecendo conexões distintas de suas diferenças sem cair em uma visão de apenas submissão e desigualdade. Ela retrata, em suas músicas, esses sujeitos como sendo as 'bichas' afeminadas, as 'bichas' pretas, as 'bichas' travestis, as pessoas trans e todos os corpos que não cabem em um padrão normativo.

Assim, Linn se torna potente para pensar esses sujeitos existentes, mas historicamente apagados dos locais de maior reconhecimento, sujeitos tidos como não inteligíveis, mas que precisam ser vistos como tendo agência, isto é, a capacidade de agir a partir da mediação cultural e social, construídas a despeito de uma negociação (PISCITELLI, 2008). Agência essa que no caso dela é confeccionada junto ao funk, que fala a partir da margem e que tende a contribuir significativamente com o processo de reconhecimento.

No clipe "Mulher"13, Linn apresenta a personagem central de sua história: "De noite pelas calçadas / Andando de esquina em esquina / Não é homem nem mulher / É uma trava feminina".

\footnotetext{
${ }^{12}$ Facina (2009) retrata que o funk, como cultura de massa, é atualmente assimilado por diversas camadas da sociedade, recebendo uma atenção especial da população jovem. Apesar disso, o funk ainda é um estilo estigmatizado no âmbito social por conta da origem (nas favelas) e das temáticas abordadas, bem como de quem canta como Mc e/ou (re)produz como $D j$. É ainda no funk, sobretudo o carioca, perceptível a história da origem associado à diáspora africana, o crescimento da música negra ligada à favela, e segmento musical mais responsável por construções identitárias étnicas e de classe.

${ }^{13}$ Disponível em: <https://www.youtube.com/watch?v=-50hUUG1Ppo\&ab_channel=LinndaQuebrada>. Acesso em: 09 nov. 2018.
} 


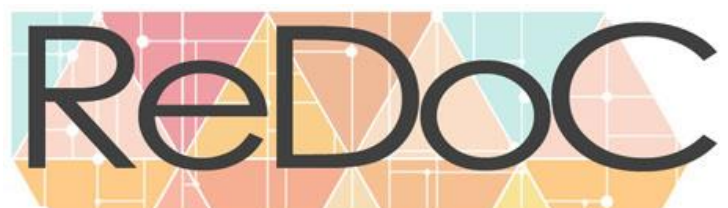

\section{Revista Docência e Cibercultura}

Essa introdução é importante porque Linn primeiramente aponta que não é uma mulher ou homem, mas sim uma travesti. Conforme Oliveira e Grossi (2014), no decorrer dos últimos anos, as categorias travesti e transexual passaram por definições e reconstruções que agiam em decorrer do tempo histórico e, principalmente, dos grupos que tentavam legitima-las ou deslegitima-las, como os discursos biomédicos, religiosos, políticos etc. Essa aparente relativização do termo é crucial para se entender que esse sujeito travesti para a cantora não é estático, mas segue em consonância com as discussões políticas da atualidade. Essa travesti sendo feminina não destoa necessariamente de um senso comum do que seria uma travesti, mas como continua Linn "Ela é diva da sarjeta, o seu corpo é uma ocupação / É favela, garagem, esgoto e pro seu desgosto / Está sempre em desconstrução", essa travesti é um sujeito se descontruindo e esse processo aqui parece estar imbricado justamente nas suas experiências na "pista"14: "Nas ruas pelas surdinas é onde faz o seu salário / Aluga o corpo a pobre, rico, endividado, milionário".

A problematização do termo travesti esbarra também no conceito de mulher, pois quando a cantora salienta a personagem como uma travesti feminina, ela apresenta uma identidade que condiz com um ser feminina, ou seja, há uma forma de ser feminina ou masculina, e essa travesti é a feminina. Não somente, no decorrer da música quando se questiona se é sempre uma mulher, Linn responde "Ela tem cara de mulher / Ela tem corpo de mulher / Ela tem jeito / Tem bunda / Tem peito / E o pau de mulher!" e "Ela é amapô ${ }^{15}$ de carne osso, silicone industrial / Navalha na boca / Calcinha de fio dental". Com isso, evidencia a construção desse corpo e dessa identidade travesti, como um modo de ser e se fazer ser, reiterando que o corpo ou seus componentes não definem a identidade, ou seja, o fato dela ter "pau" não inviabiliza a sua condição de travesti e/ou mulher.

No campo político, Linn nos permite pensar as diversas violências atreladas ao grupo que não é considerado normal por conta da identidade de gênero e/ou sexualidade. Quando ela canta

\footnotetext{
${ }^{14}$ Termo regularmente usado por travestis e transexuais para falar sobre a prostituição, seja o local onde ocorre o encontro com os/as clientes, seja o ato de prostituir ("fazer pista").

15 "Amapô" é o mesmo que "mulher", geralmente usado para as mulheres cisgêneras.
} 


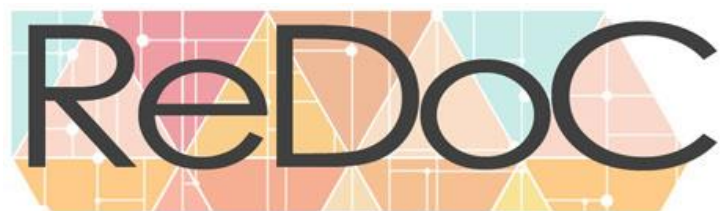

Revista Docência e Cibercultura

"Bicha estranha, louca, preta, da favela / Quando ela tá passando todos riem da cara dela" na música "Bixa Preta"16 é o corpo marcado pela sexualidade, etnia/raça, geografia, socialmente marginalizado que denuncia esse não caber em muitos espaços sociais e, por isso, recebe o deboche. Miskolci (2006) chama a atenção que as normas e convenções sociais tendem a hegemonizar os corpos e identidades, hegemonia essa que deve ser atendida a partir de um padrão já determinado pela esfera dominante. Quando um corpo, uma identidade aceita esse processo é como um conformismo às normas estabelecidas. Se essa condição não for aceita, o corpo denuncia a diferença e essa diferença é cobrada em forma de preconceito. Entretanto, é justamente na apropriação e transformação desses conceitos que causam o riso/deboche que Linn propõe um fortalecimento de si: "A minha pele preta, é meu manto de coragem / Impulsiona o movimento / Envaidece a viadagem" e se prepara para o que ela chama de destruição do "macho alfa". Essa destruição não é apenas da norma de um ser homem, mas das redes econômicas e afetivas que esses têm feito e mantido durante anos em detrimento das mulheres e do feminino, provocando uma dependência a eles, bem como procurando manter uns aos outros no topo de um certo status social. Vale ressaltar aqui que esse "macho alfa" aparece em várias músicas da Linn, mas ele não deve ser entendido necessariamente como o algoz nas situações por ela apresentada. Porque, em grande medida, ele é o ser que deseja essa figura "estranha, louca, preta da favela", flerta com ela, mas ainda reproduz o "cis-tema"17. Esse algoz pode também ser entendido como as normas reguladoras que a cantora tem reiteradamente denunciado e questionado, não necessariamente um indivíduo específico.

Ao dizer que se identifica como uma "transviada", que tem o desejo voltado preferencialmente para as "bixas" afeminadas, e na construção da imagem e exposição da corporalidade fazer uso de artifícios que desconfigure uma proeminência de um gênero atribuído ao 'sexo"18, Linn abala as normas sociais naturalizadas, normas de gênero e

\footnotetext{
${ }^{16}$ Disponível em: <https://www.youtube.com/watch?v=VyrQPjG0bbY\&ab_channel=LinndaQuebrada>. Acesso em: 09 nov. 2018.

${ }^{17}$ Entrevista disponível em: 〈https://www.youtube.com/watch?v=k5xckO1WtVc〉. Acesso em: 04 mar. 2018.

${ }^{18}$ Entendemos aqui o 'sexo' como uma representação simbólica da genitália e que a este é atribuído uma conduta socialmente instituída, conforme Butler (2003).
} 


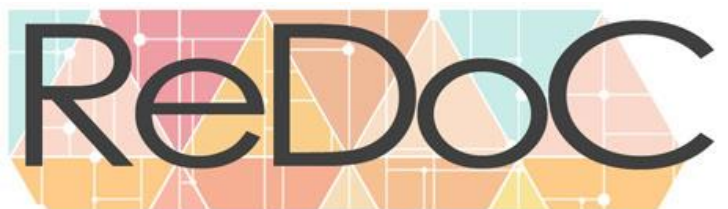

\section{Revista Docência e Cibercultura}

comportamento, de desejo pelo 'sexo oposto' e prática sexual socialmente inteligíveis como as que Butler (2003) classifica como Matriz de Inteligibilidade.

Matriz essa organizada culturalmente e naturalizada que retrata uma certa harmonia entre nascer com uma genitália, reproduzir certos comportamentos correspondente a essa genitália e se relacionar afetivo e sexualmente com um 'sexo'/gênero que seja oposto, como uma heterossexualidade compulsória. Essa noção não corresponde à figura e práticas de Linn. A desestabilidade dessa matriz provocada por Linn a conduziria para uma suposta dissidência dentro da dissidência. Entendendo que a categoria travesti é vista como uma certa dissidência da 'cis-heteronormatividade', existira na experiência de Linn uma dissidência por não ser 'cis'. Mas, por outro lado, em certa medida, mas não necessariamente, há travestis que ainda procuram reproduzir normas e convenções sociais como se fossem 'cis', geralmente em busca de uma passabilidade, experiência essa que aloca Linn também como dissidente, pois, como já discutido, isso não corresponde ao perfil de Linn. Assim, poder-se-ia pensar na existência de uma possível dissidência dentro da dissidência, isto é, da própria categoria travesti.

Contudo, se considerarmos que muitas travestis buscam a passabilidade como mulheres 'cis', isto é, buscam a reprodução da norma via a Matriz de Inteligiblidade em termos de gênero, há então uma única dissidência, isto é, desde sempre, Linn tensiona a norma, seja quando não corresponde a ela por ter 'sexo' masculino e ser travesti, ou quando não corresponde à expectativa dada via norma pelas próprias travestis reprodutoras/performatizadoras de uma inteligibilidade difundida/generalizada de ser travesti feminina, 'passável'19.

Conforme dito, as travestis ao longo dos anos procuraram uma assimilação com um corpo lido socialmente como feminino. Ao fugir disso, e ainda reivindicar essa categoria, Linn amplia

\footnotetext{
${ }^{19}$ A norma não é algo sem força sobre as experiências humanas, sejam de travestis ou não. Isso fica evidente quando, durante a finalização desse artigo, via mídias sociais, descobriu-se que Linn iniciou usos de hormônios femininos, tão recorrente entre travestis que buscam responder às expectativas de serem femininas a partir da norma. Pesquisas futuras poderão analisar o impacto dessa decisão sob a discussão que estamos desenvolvendo aqui.
}

n.1

p. 21

Jan/Abr. 2019 e-ISSN 2594-9004 


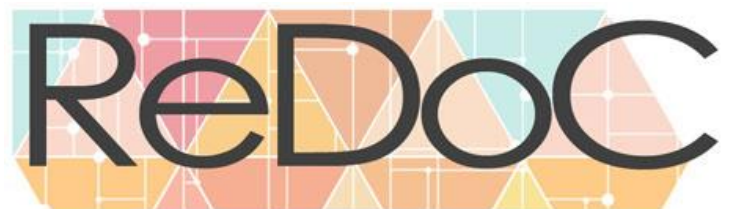

Revista Docência e Cibercultura

a possiblidade da performance do gênero gerando uma instabilidade das normativas conhecidas, ainda que as reiterando e subvertendo, em grande medida, como uma negociação de reconhecimento, legitimidade. Essa negociação se dá nas formas de apresentação que compõe, apesar de roupas e acessórios que não caracterizam de imediato um gênero, maquiagens e modos de agir que nos permite identificar um modo de ser feminino diferente do normativamente esperado. Sendo assim, não se trata de compreender Linn como a dissidência dentro da dissidência, antes, Linn expande as possibilidades de ser feminina/travesti pela sua dissidência à norma que produz inteligibilidade às mulheres 'cis' e às travestis enquanto um modo hegemônico de serem femininas.

Outra forma de ver Linn é como ela se proclama, sendo alguém que faz "terrorismo de gênero" ${ }^{20}$. Assim, Linn classifica sua existência como a apresentação e vivência de uma estética violenta diante do "cis-tema", "cis-tema" esse que tenta impor uma forma de vida específica para os sujeitos. A proposta da cantora é a de tornar sua vivência de gênero mais radical, experimentando, construindo e desconstruindo possibilidades para além das hegemônicas. Esse "terrorismo" é aqui visto como uma das principais características da cantora, que reinventa formas de ser apropriando-se das que lhe são designadas e proibidas.

Linn, ao falar de sua estética, nos mostra algo que passa pelo animalesco: "Eu busco causar um pouco de estranhamento para mim mesma e perceber como a minha estética transforma também a minha experiência e as minhas relações" ${ }^{21}$. Ela fala sobre a experimentação que passou a fazer ainda na época da escola de teatro. Sua experimentação passava principalmente pelas peças consideradas femininas e por objetos diversos. Para ela, esse processo ainda é importante, pois consegue notar que a forma como se veste altera completamente a sua relação com as outras pessoas, os olhares na rua e a relação com a família. Isso segue em consonância com esse "terrorismo de gênero" que Linn evidencia como sendo uma violência ou uma espécie de terrorismo reverso, tendo em vista que para ela a violência já atinge os corpos de pessoas

\footnotetext{
${ }^{20}$ Entrevista disponível em: <https://www.youtube.com/watch?v=k5xckO1WtVc〉. Acesso em: 04 mar. 2018.

${ }^{21}$ Entrevista disponível em: <https://www.youtube.com/watch?v=Kf_idnHJLbs\&feature=youtu.be>. Acesso em: 18 nov. 2018.
} 


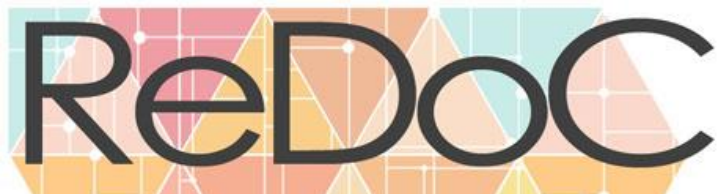

Revista Docência e Cibercultura

trans e é naturalizada, a proposta seria de devolver isso desestabilizando as normativas. Para ela, isso "tem a ver com uma estética onde a gente se posiciona de forma violenta a esse 'cistema' que nos obriga a agirmos e sermos de uma forma somente"22. Assim, ela acaba ultrapassando o binarismo de gênero não só na estética visual com figurinos inteiros feitos de lata e plástico que impossibilitam uma definição, mas sonora ao usar o feminino recorrentemente nos termos que seriam pronunciados no masculino, como "traveca", "transviada”, bem como generalizar sempre no feminino.

No campo artístico, Linn se utiliza do funk, ritmo musical carregado de estigmas, para passar uma mensagem de desconstrução e subversão da marginalização por meio da sua agência. Entretanto, essa desconstrução e subversão não demanda necessariamente a construção, seja por imposição ou negociação, de uma nova imagem, identidade, mas na reclamação desse sujeito estranho, não normativo, que se mostra vivo e subjetivo tal como outras possibilidades. Inclusive, é nesse espaço do funk que Linn possibilita fazer uma reflexão epistêmica desse estilo musical enquanto um espaço que, apesar dos estigmas em relação ao feminino e a marginalização, proporciona a ela contestar normas sociais produzidas e/ou reproduzidas nesse espaço e se tornar reconhecida em diversos outros espaços onde o funk talvez não chegasse, como fazer uma pequena turnê na Europa.

\section{(Des)construção, (re)significação}

Uma identidade dissidente, abjeta, abarca diversas identidades e corpos que não são considerados importantes, que tem até mesmo a condição de humanidade questionada (BUTLER, 2001). Essas identidades são recusadas pelo outro devido a oposição à norma, mas não ocorre necessariamente a sua extinção, pois ainda se torna necessário esse referencial para manter o que se construiu como normal. A abjeção tende a negativar a experiência dissidente

${ }^{22}$ Entrevista disponível em: 〈https://www.youtube.com/watch?v=k5xckO1WtVc $>$. Acesso em: 04 mar. de 2018〉. Acesso em: 15 nov. 2018. 


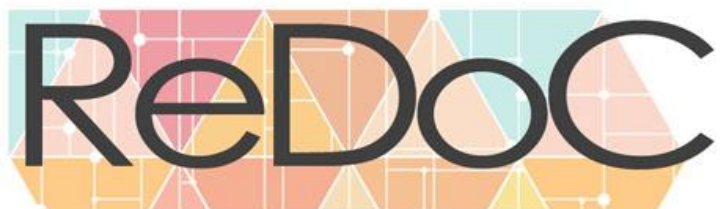

\section{Revista Docência e Cibercultura}

enquanto sujeito, limitando ou recusando a sua autonomia. Para Linn, a sociedade precisa de alguém que fuja da norma para se entender o que é desprezível, rejeitado. É projetada uma exceção para se entender a regra ${ }^{23}$.

Linn é caracterizada por um corpo dissidente, corpo esse que se rebela contra a norma e que procura reivindicar o direito de existir, caracterizando assim a instabilidade do gênero incitada por Butler (2003) na alegação de que corpos ditos masculinos podem ser femininos e corpos ditos femininos podem ser masculinos. Isso porque a autora aponta para a construção cultural do gênero e da sua capacidade de perpassar por ambos os 'sexos' binários. É sendo dissidente nessa lógica, no que tange à expressão de gênero e à sexualidade que Linn confecciona sua identidade.

Desde o século XVIII a sociedade tem vivido uma espécie de 'repressão sexual'. Entretanto, essa 'repressão' foi, em certa medida, o motor de produção de sexualidade. Esse certo impedimento de se falar sobre sexo e da prática, na verdade, é o que fez proliferar os discursos sobre o sexo. Entretanto, instituições como família, igreja, escola buscavam o poder, o controle do indivíduo e não necessariamente a redução da prática do sexo (FOUCAULT, 1988). É, portanto, para Foucault um momento importante de disputas pelo controle e poder na sociedade e não necessariamente de uma repressão, o que pode colocar em suspenção o termo, mas que de alguma forma refletiu nas condutas sociais dos indivíduos.

A história de (des)construção de Linn aparece em "A Lenda"24: "Eu fui expulsa da igreja (ela foi desassociada) / Porque 'uma podre maçã deixa as outras contaminada' / Eu tinha tudo pra dar certo e dei até o cu fazer bico / Hoje, meu corpo, minhas regras, meus roteiros, minhas pregas / Sou eu mesma quem fabrico". Isso nos remete a esse mote repressivo de sexualidades que está para além de uma norma. A 'sociedade disciplinar' (FOUCAULT, 2008) remete a um movimento social de conduzir o sujeito a obedecer, atender as demandas de um grupo

\footnotetext{
${ }^{23}$ Entrevista disponível em: <https://www.youtube.com/watch?v=RgTbQH3N6S8\&t=16s>. Acesso em: 15 mar. 2017.

${ }^{24}$ Disponível em: <https://www.youtube.com/watch?v=g3w-t585D54\&ab_channel=Showlivre>. Acesso em: 09 nov. 2018.
} 


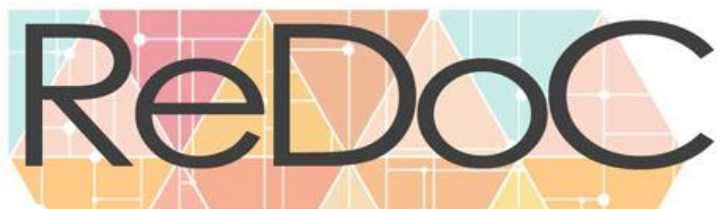

\section{Revista Docência e Cibercultura}

específico de poder. Esse disciplinar é esquematizado de forma a fazer com que o indivíduo não o conteste, que ele o naturalize e acabe se tornando o vigia de si mesmo, mas não de modo conformista, pois os indivíduos estão condicionados em estrutura e em diversas esferas de poder. A feminilidade partindo de uma figura designada socialmente como masculina é então freada e condicionada a moldes 'universais'.

Linn acredita que o funk, até mesmo pela marginalização social relacionada juntamente aos campos de reprodução desse ritmo (como as favelas), também produza discursos sobre o 'sexo', produz e reproduzir sexualidade, mas sobre um desmerecimento maior em relação aos outros ritmos musicais por conta das pessoas que cantam ou são retratadas estarem geralmente em uma condição marginalizada ${ }^{25}$. Assim sendo, a aproximação com o ritmo também esbarra nos próprios interesses da cantora em falar sobre temáticas específicas, para além das suas possibilidades de acesso. $\mathrm{O}$ funk produzido por ela traz nas letras incitação ao reconhecimento de si, a dominar e conhecer o próprio corpo, bem como o questionamento dos desejos construídos pela sociedade.

A sociedade que vigia e disciplina, muitas vezes via a punição, é concebida através de 'papeis'/expectativas, sujeitos realizando performances de questionar a identidade de outros sujeitos que não se enquadram dentro do que o sistema delimitou. Para Linn, a denúncia que o sujeito faz, como em chamar alguém de 'viado' na rua, é como apontar o abjeto. O abjeto "relaciona-se a todo tipo de corpos cujas vidas não são consideradas 'vidas' e cuja materialidade é entendida como "não importante"” (PRINS; MEIJER, 2002, p. 161). Dito de outro modo,

As imagens corporais que não se encaixam em nenhum dos gêneros tidos como em oposição, masculino e feminino, ficam fora do humano, a rigor, constituem o domínio do desumanizado e do abjeto, em contraposição ao qual o próprio humano se estabelece (Idem, 2002, p. 162).

${ }^{25}$ Entrevista disponível em: <https://www.youtube.com/watch?v=X_oQL59VUu0\&t=887s >. Acesso em: 15 mar. 2017. 


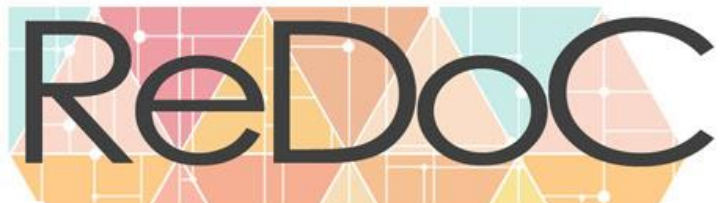

Revista Docência e Cibercultura

Assim, esse 'viado' ecoado na rua serve para anunciar que esse outro está descumprindo uma norma, assim ele (o vigia) também tem a oportunidade de reafirmar o seu 'papel social'. Segundo Linn, o vigia "tem que denunciar e fazer com que as outras pessoas percebam que aquilo ali não é homem porque quando ele faz isso, ele está dizendo 'porque eu sou homem e o meu dever é denunciar"'26.

No que tange a escolha do funk para se expressar, Linn afirma que a representatividade do feminino sempre foi desvalorizada em diversos ritmos musicais, entretanto, é no funk que é possível levantar uma voz, constituir um diálogo com a periferia, além de ser esse um dos ritmos que dão voz para falar sobre as vivências de identidades até então silenciadas pela sociedade, apesar dessa possibilidade não ser fundamentalmente uma característica do funk, conforme será discutido no próximo capítulo ${ }^{27}$.

\section{Funk como possibilidade de criação de desejo}

No Brasil, originado em um sistema de marginalização, o funk chegou nos anos 70 e se propagou de forma a atingir todas as parcelas da sociedade. Ele registra desde o início um discurso de descontentamento dos povos marginalizados e suas músicas denunciavam mazelas sociais, assim como o Hip hop.

Para Monteiro, apesar da popularização do funk, as/os artistas não buscavam necessariamente um investimento em apresentações mais rebuscadas:

O funk conquistou bastante espaço na mídia, principalmente por meio de apresentações dos cantores em programas de TV, rádio e televisão; o que contribui para a população do funk em meados de 2000 internacionalmente. Algo a se comemorar, pois um movimento que vinha da periferia estava conquistando o mundo.

\footnotetext{
${ }^{26}$ Entrevista disponível em: <https://www.youtube.com/watch?v=RgTbQH3N6S8\&t=16s>. Acesso em: 15 mar. 2017.

${ }^{27}$ Entrevista disponível em: <https://www.youtube.com/watch?v=owO2jQndWX8>. Acesso em: 15 mar. 2017.
} 
Entretanto, mesmo com o sucesso, o funk não tinha uma preocupação significativa com a comunicação, podemos dizer que poucos eram os artistas que trabalhavam com videoclipes, edições especiais, raras exceções, como a dupla Claudinho e Buchecha tinham essa preocupação. (2014, p. 5)

É mediada por esse ritmo musical que Linn compartilha a própria história, casualidades, preconceitos sofridos por ser "travesti preta e periférica", mas ao contrário do que era nos anos 2000, investindo em parcerias com outras/os artistas LGBTs, bem como em videoclipes e participações em programas de TV e pela internet, sobretudo no YouTube. Para ela, a música é um movimento de ocupação, de resistência, de existência e o funk é uma explosão cultural, mas ela ressalta que até mesmo essa performance de cantora não é algo fixo: "Eu sei que estou cantora, que estou ocupando esse espaço, mas eu não sei qual é o próximo passo" ${ }^{28}$. É a instabilidade e o movimento os combustíveis utilizados por Linn.

A cantora vai na contramão dos modelos de identidades difundidos pela mídia e apreendidos na educação que estão cada vez mais difíceis de serem obtidos. A sociedade, entretanto, ainda continua na busca dessa assimilação midiática. Para se alcançar esse objetivo, é necessária uma dedicação intensa e essa não só é cultuada como também é controlada e vigiada por outros que também estão sujeitos a se enquadrar (MISKOLCI, 2006).

Essa assimilação perpassa o sistema binário (masculino - feminino) que se faz aparentemente lógico na caracterização do gênero homem e mulher, vindo a ser constituído a partir ou junto ao 'sexo'. Vinculando o comportamento expresso socioculturalmente ao 'sexo', ao gênero e à genitália, criando assim uma determinação ideal. Conforme Bento aponta, há uma tentativa de alocar uma questão do campo biológico, da natureza no que tange a transexualidade, como se postulasse um imperativo de que "a natureza constrói a sexualidade e posiciona os corpos de acordo com as supostas disposições naturais" (2008, p. 17), o que para a autora é uma problemática, inclusive, postulada no sistema binário. Os corpos devem então ser construídos a partir dessa determinação que, apesar de se apresentar como natural - sendo

\footnotetext{
${ }^{28}$ Entrevista disponível em: < https://www.youtube.com/watch?v=A9KKFSyvlS4>. Acesso em: 15 de mar. 2017.
} 


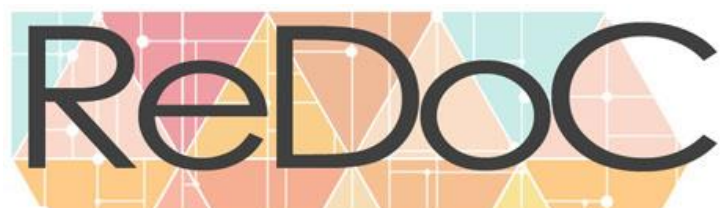

\section{Revista Docência e Cibercultura}

mais especificamente naturalizada - é ainda construída, demonstrando que a possibilidade de subversão e/ou outra montagem desse corpo, bem como expressão de gênero são possíveis.

Na perspectiva aqui abordada, essa crítica culmina com a que a cantora propaga no funk, crítica essa que contesta a lógica binária por conta da normatividade compulsória que tentam lhe impor para um se adequar ao considerado normal, como quando a cantora diz em "Pirigoza"29: "Então olha só, doutor! / Saca só que genial / Sabe a minha identidade? / Nada a ver com xota e pau!". A análise permite compreender os processos de resistência, bem como a apropriação do funk como performance dirigida e/ou mediação discursiva em uma constituição de si mesma.

O interessante de pensar a Linn é desde quando ela começa no cenário musical, aliás, de como ela chega nesse local. Após ter passado por companhias de teatro, Linn começa a experimentar a música e, mais especificamente, o funk, como sendo o ritmo musical que ela percebe a possibilidade de expor suas inquietudes em relação aos atravessamentos que lhe atingem diretamente. Linn salienta que isso tem ocorrido de forma orgânica, pois ela nunca planejou ser cantora. A ideia de cantar surge logo após ver uma amiga do teatro que começou a fazer música. Assim, resolveu tentar e foi conhecendo pessoas e fazendo parcerias de criação até o lançamento do disco Pajubá. Esse disco foi realizado com financiamento coletivo através de um site. Com uma meta de $\mathrm{R} \$ 45$ mil, Linn arrecadou $\mathrm{R} \$ 49.980,00^{30}$ para produzir o disco que foi lançado no final de 2017.

Vale ressaltar que o funk produzido pela cantora não é como o funk analisado por Monteiro (2014), isto é, dos anos 70 ou de finais da década de 2010, em que as 'batidas' eram reconhecidamente/exlusivamente do funk. Linn mescla essas 'batidas' do funk com outros ritmos musicais que permite uma flexibilização de sua música/harmonia e, inclusive, a permite acessar novos espaços com esse estilo.

\footnotetext{
${ }^{29}$ Disponível em: <https://www.youtube.com/watch?v=7kZ4Xh0mhik\&ab_channel=LinndaQuebrada>. Acesso em: 10 de nov. 2018.

${ }^{30}$ Financiamento disponível em: <https://www.kickante.com.br/campanhas/linn-da-quebrada-bixa-pode-fazerum-pedido-0>. Acesso em: 18 de nov. 2018.
} 
A reflexão de produzir música também passa pela comercialização. Apesar de um grande volume de doações para a o disco, a venda e a inserção em algumas plataformas, bem como a participação em alguns programas necessitam de algumas concessões, mas ela aposta que é justamente a forma que produz a própria música que a faz permanecer sendo ouvida. Linn diz que não canta só sobre si mesma, mas sobre outras pessoas que assim como ela querem se ver e ouvir, e esse processo ainda serve de ponte para encontros de corpos e vidas semelhantes.

Apesar de não ser uma artista que produz para/na internet, Linn se destaca nessa rede, principalmente com o primeiro videoclipe ("Enviadescer" ${ }^{31}$ ) divulgado no YouTube, sendo o primeiro passo a nível nacional de reconhecimento do seu trabalho enquanto artista, performer. A música que até então estava em um processo de experimentação, torna-se o motor de articulação e manifestação política de Linn.

Um dos conceitos de Butler (2015) para pensar o sujeito é o desejo. Não só o sujeito ou não necessariamente o sujeito, mas a agência desse sujeito, pois é a atividade, a consciência reflexiva de resistir e/ou subverter convenções que consiste na caracterização da agência. Para a autora, é o desejo o motor que vai guiar ou impulsionar a mudança, que vai desestabilizar o sistema convencional. Linn propõe o funk como uma possibilidade de criar ou recriar os seus desejos, desejos esses que as músicas geralmente não produzem devido a uma 'cisheteronorma' que canta sobre corpos e desejos hegemonicamente legitimados.

Sobre essa produção do desejo, Linn contesta "a minha história não é contada, os meus desejos não são criados, os meus afetos, os meus desejos sexuais, esses ficam mantidos escuro" ${ }^{32}$. Foi partindo dessa necessidade de se ver na música, de se reconhecer nas letras e perceber possibilidades de afeto mais próximas a sua realidade que a cantora começa a produzir no funk, mas uma produção no sentido de contar histórias e não necessariamente de criar novas,

\footnotetext{
${ }^{31}$ Disponível em: <https://youtu.be/saZywh0FuEY>. Acesso em 10 nov. 2018.

${ }^{32}$ Entrevista disponível em: <https://www.youtube.com/watch?v=X_oQL59VUu0\&feature=youtu.be>. Acesso em: 10 nov. 2018.
} 


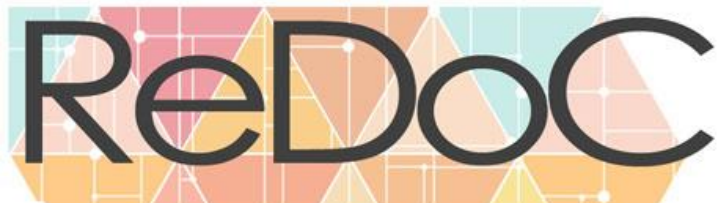

Revista Docência e Cibercultura

pois para a cantora, a história já existe, só não é declarada, cantada, bem como os desejos. O funk torna-se a ferramenta de contar histórias fazendo emergir questões que já existem para um determinado seguimento, mas que são abafadas ou silenciadas. Isso não significa necessariamente que o funk é um espaço inclusivo, muito pelo contrário, como apontado, a problemática envolvendo esse ritmo também diz respeito a seus posicionamentos considerados machistas em relação ao feminino. O que se torna relevante nessa questão é compreender que o ritmo não está fechado em si mesmo, o crescimento e sucesso de uma travesti nesse campo é um exemplo da incongruência de um paradigma visto como intrínseco de que o funk só poderia ter uma forma.

\section{"Se tu quiser ficar comigo, boy, vai ter que enviadescer" 33}

Tanto a estética quanto a música de Linn provoca uma expansão da dimensão de "ser travesti" ou daquilo que é entendido como tal. Isso porque Linn não é uma travesti que tem 'peitão', 'bundão', toda siliconada, como poderia recorrer um conceito comum, e nem sempre lhe é dado o reconhecimento de uma identidade feminina. A concepção de suas performances passa por roupas e adereços considerados masculinos e roupas e adereços considerados femininos, e essa não tem sido necessariamente uma tentativa da Linn de se abster de um gênero, mas sim de problematiza-lo.

Na música "Enviadescer"34, Linn convoca o "macho discreto" para dizer que o real interesse dela não é nele, mas sim nas 'bichas' porque ela gosta “das que são afeminadas / Das que mostram muita pele, rebolam, saem maquiada". Esse momento é onde a Matriz de Inteligibilidade perde força, pois Linn não está preocupada em reiterar um papel feminino que se harmonizaria afetivamente com o masculino, pelo contrário. Ela deseja, ou pelo menos

\footnotetext{
${ }^{33}$ Disponível em: <https://www.youtube.com/watch?v=saZywh0FuEY\&ab_channel=LinndaQuebrada>. Acesso em: 09 nov. 2018.

${ }^{34}$ Idem.
} 


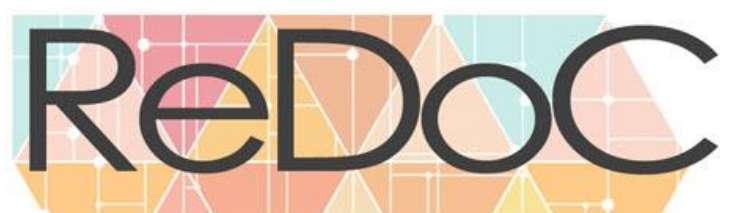

\section{Revista Docência e Cibercultura}

produz a ideia do desejo, por outras "transviadas" assim como ela. "Mas não tem nada a ver com gostar de rola ou não / Pode vir, cola junto as transviadas, sapatão". Assim, evidenciando também que esse tornar-se "viada" não tem a ver com o gênero e/ou a sexualidade, mas com uma manifestação política. A proposta é, portanto, se apropriar do feminino (ainda que reitere parte da norma no sentido de identificar-se como feminina) sem que isso remeta a uma condição de desejo pelo masculino, pois ela deixa claro "Eu não tô interessada no seu grande pau ereto".

O clipe ainda traz cenas com várias mulheres e homens trans ou não que se misturam entre o feminino e o masculino nos figurinos, maquiagem, performance. $\mathrm{O}$ que a princípio parece ser uma manifestação na rua de identidades diversas reclamando o feminino para si. Essa reclamação soa como a proposta de se contestar a feminilidade que geralmente é criticada tanto nos corpos que podem manifesta-la quanto nos que devem reprimi-la, mulheres e homens respectivamente.

Isso culmina com a apropriação de termos que seriam usados como xingamentos: viado, transviado/a, bicha, e a quebra de expectativa de desejos, de discursos, de comportamentos que a ela foi designada por ser uma travesti. É nesse rompimento que Linn se mostra possível para além daquilo que ela foi estereotipada, não só quebrando a expectativa, mas reformulando as categorias e nos apresentando possibilidades não pensadas.

Ao propor outras possibilidades, Linn tentar romper com o que ela chama de "romancis ${ }^{35}$ ", ou seja, uma confecção de histórias que abrangem a pessoa cisgênera e heterossexual, sendo uma espécie de fórmula de manutenção desse status, ignorando a existência de outras personagens que fujam desse padrão, buscando inclusive a circulação do dinheiro em determinados espaços e arranjos familiares. Com isso, Linn procura externalizar essa provocação de que a norma faz de se mostrar norma, quando ela conhece outras possibilidades e até mesmo normativas dentro do mesmo "cis-tema". Ao ser questionada sobre ser o amor uma ferramenta de auto estímulo e ensino da população LGBT para com as pessoas devido a

\footnotetext{
${ }^{35}$ Entrevista disponível em: <https://www.youtube.com/watch?v=m1WBvSRMgjE\&feature=youtu.be>. Acesso em: 03 set. 2018.
} 


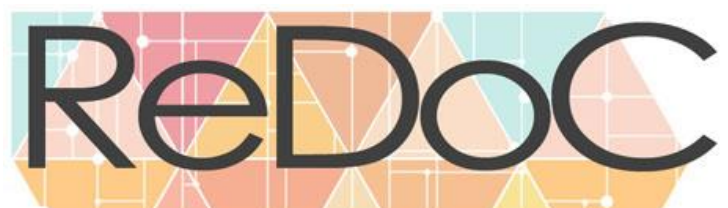

\section{Revista Docência e Cibercultura}

andarem de mãos dadas e trocarem afetos em público, Linn defende que, na verdade, o amor existe como uma das principais ferramentas do sistema 'cis-heteronormativo'.

Conforme Linn, "se você liga a televisão, se você vê as novelas, o grande drama ou a grande trama das novelas é o quê? É o amor. Se você vai ler um livro o que se incentiva, o que

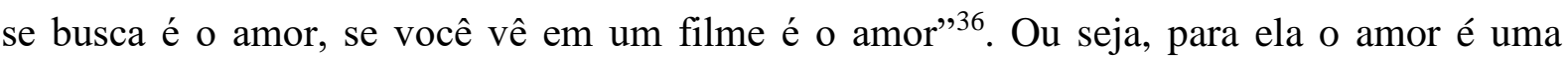
ferramenta, mas usada geralmente por e para pessoas cisgêneras, heterossexuais, com uma determinada classe social (para a manutenção desta). Geralmente essas personagens femininas ou feminilizadas são alocadas como as que se interessam pelo romance/amor, e os personagens masculinos ou masculinizados como os provedores de dinheiro. Isso é importante e interessante porque a cantora não propaga nas suas músicas a busca por um amor romântico (como ela denuncia ocorrer em outras instâncias), mas sim a possibilidade de se relacionar para além do afeto, apenas sexualmente, com outras pessoas fora da 'cis-heteronormatividade'. É como se a 'sexualidade mais crua' recebesse uma maquiagem mais romântica que a cantora prefere borrar porque acredita que essa maquiagem tende a subjugar os sujeitos, sobretudo a mulher, e seus desejos.

\section{Considerações Finais}

Analisando o desenvolvimento da Linn no funk e sua ascensão no campo artístico, é possível compreender que o uso que ela faz da música é político e singular, mas não único, pois ainda há outras/os artistas antes dela e na atualidade que de alguma forma quebram ou contestam o sistema hegemônico da 'cisheteronormatividade'. Além disso, a possibilidade que ela traz com as batidas características do ritmo musical também poderiam remeter a um entretenimento, tendo em vista que suas apresentações com plateia envolvem danças e movimentos característicos do ritmo, contudo, Linn sempre evidencia que sua proposta é de ser ouvida. Estar como cantora, o que para ela não é estático, é a possibilidade que encontrou no momento de se fazer ouvir. O que se destaca em especial na cantora é a forma como conduz

\footnotetext{
${ }^{36}$ Idem.
} 


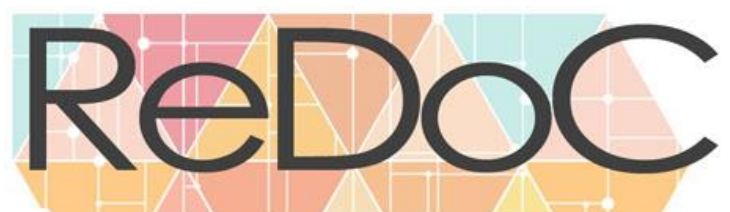

Revista Docência e Cibercultura

suas críticas e as apropriações que faz tanto dos conceitos a ela aplicados, como de um discurso mais acadêmico. Os posicionamentos e articulações parecem transpor as discussões 'transviadas' para o funk centrando na experiência que a cantora tem de sua condição mais marginalizada, condição essa que a faz reverter a lógica e a impulsiona e a viabiliza como referência.

Linn deixa evidente a todo o momento a sua relação de problematização sociocultural com conceitos naturalizados, discussão essa que revisa os conceitos já estabelecidos de abjeto e dissidente, gerados na própria cultura em que os sujeitos estão inseridos a partir da existência de um comportamento médio ou ideal que se harmonizaria com o funcionamento do sistema social, bem como de possibilidades de construção de identidades, sobretudo pautadas pelas interseções e mediações as quais Linn se coloca e é alocada diante dessa visibilidade, como travesti, negra, periférica.

A identidade propagada pela cantora a respeito de si mesma, mas não somente, pois nesse processo de questionamento identitário ela expande suas reflexões para corpos que, como o dela, estão sob uma vigia mais rígida da sociedade, permite assimilar a existência e a experiência como articuladores da produção de si mesma e não como determinantes.

Ao se colocar como "terrorista de gênero" e buscar destruir o "cis-tema" e o "macho alfa", Linn parece ser uma figura intragável que não caberia em nenhum espaço, principalmente os mais inclusivos, por conta de uma espécie de violência simbólica e retórica que ela fala ao defender a própria existência. Contudo, ao que se percebe, principalmente no Youtube, a cantora ganha mais e mais espaço, nos seus clipes o número de visualizações é considerado bom dentro da plataforma e Linn tem se destacado em outros campos, como em filmes e documentário premiado internacionalmente ${ }^{37}$. Isso é crucial para se perceber que a cantora apesar de ganhar mais fãs por conta de suas apostas performáticas e problemáticas levantadas,

\footnotetext{
${ }^{37}$ O documentário "Bixa Travesty", que conta a história da cantora, recebeu em 2018 o prêmio Teddy Award do Festival Internacional de Cinema de Berlim, na Alemanha, um dos mais importantes na área de cinema LGBT. O mesmo documentário recebeu 4 prêmios também no Brasil no Festival de Cinema de Brasília.
} 


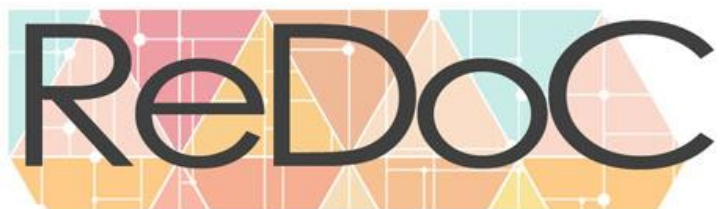

\section{Revista Docência e Cibercultura}

é uma figura estranha daquilo que é conhecido, escutado, visto. Sua estética e fala compõem um sujeito que não é comum, um sujeito que brinca com o gênero e que passa muitas vezes até pelo animalesco.

Gomes (2016) ao fazer uma análise da identidade de gênero no movimento funk e a relação com a mídia, expõe a singularidade composta por uma funkeira trans que faz surgir um interesse midiático de acesso por conta de uma visibilidade perversa que busca, antes de tudo, explorar esse sujeito e sua condição, reduzindo, simplificando as pautas das/os artistas e provocando muitas vezes conceitos confusos sobre determinada questão. Isso torna-se um ponto marcante para entender a procura cada vez maior pela cantora na plataforma, pois ainda há uma certa complexidade dela ao se colocar e falar de suas pautas que saltam como discrepante do esperado e, de certa forma, fascina o ouvinte que até então só via mais uma travesti. Isso, pensando em mercado editorial, serve para a cantora como um certo chamariz, como se essa estranheza fosse um produto de venda. Apesar de a todo o momento se colocar como alguém que produz mais como um ato político, Linn parece estar ciente desse mercado, bem como das dificuldades de acesso e permanência nele e da necessidade mercadológica de suas músicas para serem mais acessadas/vendidas, apesar de relutar com as concessões e limitações de suas performances (como o uso de termos considerados palavrões).

Conforme verificado no YouTube, Linn ao decorrer dos últimos 2 anos, desde o primeiro vídeo na plataforma, passou a ser buscada para entrevistas em diversos canais que não tratam necessariamente sobre corpo, sexualidade e gênero, mas que viram na cantora uma subjetividade destoante que, conforme dito, conversa muito com parte dos discursos acadêmicos sobre essas temáticas. Talvez Linn pudesse ser caracterizada com a forma de expor os conceitos em uma linguagem mais fluída e acessível ao público, principalmente para o público que ela canta: população LGBT, negra e periférica.

Fica manifesto pela cantora que seu posicionamento não é o de criar uma organização de novas identidades, mas de permitir que as existentes ganhem vozes, ganhem espaços. E apesar de sua contundente manifestação a uma destruição da norma, é preciso entender que a 


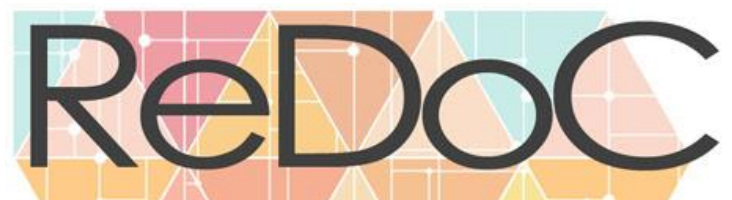

Revista Docência e Cibercultura

proposta é de denunciar essa norma, pois ela não é necessariamente o normal e nem o ideal, provocando deslegitimações de sujeitos e experiências. A reinvindicação passa por uma existência que não seja pautada em um sistema de compressão sexual e generificado, mas por uma 'liberdade' de existência e experiência que, em certa medida, pode reiterar a norma, como às vezes ocorre em Linn ao fazer uso de maquiagem, salto alto, reivindicando e evidenciando a "trava feminina", mas que não fique fadada a ela.

\section{REFERÊNCIAS}

AMARAL, Adriana. Etnografia e pesquisa em cibercultura: limites e insuficiências metodológicas. Revista USP, Brasil, n. 86, p. 122-135, ago. 2010. ISSN 2316-9036. Disponível em: <http://www.revistas.usp.br/revusp/article/view/13818>. Acesso em: 05 mar. 2018.

BENEDETTI, Marcos Renato. Toda feita: o corpo e o gênero das travestis. Dissertação de Mestrado, Programa de Pós-Graduação em Antropologia Social, Universidade Federal do Rio Grande do Sul, Porto Alegre, 2000.

BENTO, Berenice Alves de Melo. O que é transexualidade. São Paulo: Brasiliense, 2008.

BUTLER, Judith. Corpos que pensam: sobre os limites discursivos do "sexo". In: LOURO, Guacira Lopes (Org.). O corpo educado: pedagogias da sexualidade. Belo Horizonte: Autêntica, 2001.pp. 151-172.

BUTLER, Judith. Problemas de gênero: feminismo e subversão da identidade. Rio de Janeiro: Civilização Brasileira, 2003.

BUTLER, Judith. Relatar a si mesmo: crítica da violência ética. Tradução Rogério Betonni. 1 ed. 1 reimp. Belo Horizonte: Autêntica, 2015.

DUQUE, Tiago. Montagens e Desmontagens: desejo, estigma e vergonha entre travestis adolescentes. São Paulo: Annablume, 2011.

DUQUE, Tiago. Gêneros incríveis: um estudo sócio-antropológico sobre as experiências de (não) passar por homem e/ou mulher. Campo Grande, Editora da UFMS, 2017.

FACINA, Adriana. "Não me bate doutor": Funk e criminalização da pobreza. In: V Encontro de Estudos Multidisciplinares em Cultura - ENECULT, Bahia, Anais... Salvador: 
Faculdade de Comunicação da Universidade Federal da Bahia, mai. 2009. Disponível em: <http://www.cult.ufba.br/enecult2009/19190.pdf>. Acesso em: 05 mar. 2018.

FOUCAULT, Michel. História da Sexualidade I: A vontade de saber. Rio de Janeiro: Edições Graal, 1988.

FOUCAULT, Michel. Vigiar e Punir: nascimento na prisão. Rio de Janeiro: Vozes, 2008. pp. 162-187.

GOMES, Maria Carmen Aires. Identidade de gênero no movimento funk: um estudo explanatório crítico de notícias jornalísticas brasileiras. Ilha do Desterro A Journal of English Language, Literatures in English and Cultural Studies, [S.1.], v. 69, n. 1, p. 183200, jan. 2016. ISSN 2175-8026. Disponível em: <http://www.scielo.br/pdf/ides/v69n1/2175-8026-ides-69-01-00183.pdf >. Acesso em: 15 mar. 2017.

GREEN, James. Além do carnaval - homossexualidade masculina no Brasil do século XX. São Paulo: Editora da UNESP, 2000.

LOURO, Guacira Lopes. Teoria queer - uma política pós-identitária para a educação. Revista Estudos Feministas, Florianópolis, v. 9, n. 2, p. 541, jan. 2001. ISSN 1806-9584. Disponível em: <https://periodicos.ufsc.br/index.php/ref/article/view/S0104026X2001000200012/8865>. Acesso em: 05 mar. 2018.

MISKOLCI, Richard. A Teoria Queer e a Sociologia: o desafio de uma analítica da normalização. Sociologias. Porto Alegre: 11, n. 21, 2009. pp. 150-182. Disponível em: <http://www.scielo.br/pdf/soc/n21/08.pdf>. Acesso em: 15 mar. 2017.

MISKOLCI, Richard. Corpos elétricos: do assujeitamento à estética da existência. Estudos Feministas, Florianópolis, v. 14, n. 3, pp. 681-693, jan. 2006. ISSN 1806-9584. Disponível em: <https://periodicos.ufsc.br/index.php/ref/article/view/S0104-026X2006000300006>. Acesso em: 15 mar. 2017.

MISKOLCI, Richard. Não somos, queremos - Notas sobre o declínio do essencialismo estratégico. Comunicação apresentada na Mesa Novas Perspectivas e Desafios Políticos Atuais do evento Stonewall 40 + o que no Brasil?, realizado em Salvador, em 17 de setembro de 2010. Disponível em: <http://www.ufscar.br/cis/wpcontent/uploads/N\%C3\%A3o-Somos-queremosRichardMiskolci.pdf >. Acesso em: 15 mar. 2017.

MISKOLCI, Richard. Novas conexões: notas teórico-metodológicas para pesquisas sobre o uso de mídias digitais. Revista Cronos, [S.1.], v. 12, n. 2, jun. 2011. ISSN 1982-5560. 
Disponível em: <https://periodicos.ufrn.br/cronos/article/view/3160>. Acesso em: 05 mar. 2018.

MONTEIRO, Vanessa Estevam Carlos. Funk da Ostentação: uma análise semiótica do videoclipe "Na pista eu arraso", do Mc Guime. Disponível em: <http://www.portalintercom.org.br/anais/nordeste2014/resumos/R42-0416-1.pdf >

Acesso em: 15 mar. 2017.

OLIVEIRA, Melissa Barbieri de; GROSSI, Miriam Pillar. A invenção das categorias travesti e transexual no discurso científico. Rev. Estud. Fem., Florianópolis, v. 22, n. 2, p. 699701, ago. 2014. Disponível em: <http://www.scielo.br/scielo.php?script=sci_arttext\&pid=S0104026X2014000200025\&lng=en\&nrm=iso>. Acesso em: 09 nov. 2018.

PISCITELLI, Adriana. Interseccionalidades, categorias de articulação e experiências de migrantes brasileiras. Sociedade e Cultura [on line], v. 11, n. 2, pp. 263-274, 2008 (junhodezembro). Disponível em: <http://www.redalyc.org/articulo.oa?id=70311249015>. Acesso em: 20 nov. 2017.

PRINS, Baukje; MEIJER, Irene. Como os corpos se tornam matéria: entrevista com Judith Butler. Tradução: Susana Funck. Revista Estudos Feministas, v. 10, n. 1, p. 155-167, jan. 2002. Disponível em: <http://www.scielo.br/scielo.php?script=sci_arttext\&pid=S0104026X2002000100009\&lng=en\&nrm=iso>. Acesso em: 15 nov. 2017.

RAMÍREZ, Boris. Colonialidade e cis-normatividade. Entrevista com Viviane Vergueiro. Iberoamérica Social: revista-red de estudios sociales (III), pp. 15-21, 2014. Disponível em: $<$ http://iberoamericasocial.com/colonialidade-e-cis-normatividade-conversando-comviviane-vergueiro>. Acesso em: 19 nov. 2018.

SANTOS, Welson Barbosa; DINIS, Nilson Fernandes. Adolescência heteronormativa masculina: entre a construção "obrigatória" e desconstrução necessária. DOI 10.5216/o.v13i2.23273. OPSIS, [S.1.], v. 13, n. 2, p. 129-149, fev. 2014. ISSN 2177-5648. Disponível em: <https://www.revistas.ufg.br/Opsis/article/view/23273/15911>. Acesso em: 19 fev. 2018.

SILVA, Hélio R. S. Travesti: a invenção do feminino. Rio de Janeiro: Relume-Dumará: ISER, 1993. 